\title{
Dual-Labeled Trastuzumab-Based Imaging Agent for the Detection of Human Epidermal Growth Factor Receptor 2 Overexpression in Breast Cancer
}

\author{
Lakshmi Sampath $^{1-3}$, Sunkuk Kwon ${ }^{1}$, Shi Ke ${ }^{1}$, Wei Wang ${ }^{1}$, Rachel Schiff ${ }^{3}$, Michel E. Mawad ${ }^{1}$, and \\ Eva M. Sevick-Muraca ${ }^{1-3}$ \\ ${ }^{1}$ Division of Molecular Imaging, Department of Radiology, Baylor College of Medicine, Houston, Texas; ${ }^{2}$ Molecular Physiology and \\ Biophysics, Baylor College of Medicine, Houston, Texas; and ${ }^{3}$ The Baylor Breast Center, Baylor College of Medicine, Houston, Texas
}

Overexpression of the human epidermal growth factor receptor (HER) family has been implicated in cancer because of its participation in signaling pathways regulating cellular proliferation, differentiation, motility, and survival. In this work, we exploited the extracellular binding property of trastuzumab, a clinically therapeutic monoclonal antibody to the second member of the HER family (HER2), to design a diagnostic imaging agent, $\left({ }^{111} \mathrm{In}-\right.$ DTPA $)_{n}$-trastuzumab-(IRDye $\left.800 C W\right)_{m}$, that is dual labeled with ${ }^{111} \mathrm{In}$, a $\gamma$-emitter, and a near-infrared (NIR) fluorescent dye, IRDye $800 \mathrm{CW}$, to detect HER2 overexpression in breast cancer cells. The stoichiometric ratios " $n$ " and " $m$ " refer to the number of diethylenetriaminepentaacetic acid dianhydride (DTPA) and IRDye $800 \mathrm{CW}$ molecules bound per trastuzumab molecule, respectively. Methods: Fluorescence microscopy and confocal microscopy were used to determine the molecular specificity of (DTPA) $)_{n}$-trastuzumab-(IRDye800) $)_{m}$ in vitro in SKBr3 (HER2positive) and MDA-MB-231 (HER2-negative) breast cancer cells.

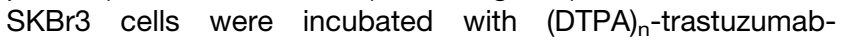
(IRDye800 $)_{m}$ or IRDye800CW or pretreated with trastuzumab or

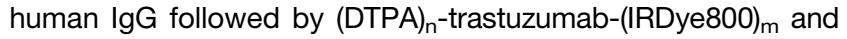
examined under a fluorescence microscope. For in vivo characterization, athymic nude mice bearing HER2-overexpressing SKBr3-luc subcutaneous xenografts were injected intravenously with $\left({ }^{111} \mathrm{In}-\mathrm{DTPA}\right)_{\mathrm{n}}$-trastuzumab-(IRDye800 $)_{\mathrm{m}}$ and imaged with SPECT and NIR fluorescence imaging at $48 \mathrm{~h}$. Tumor-bearing mice were also injected intravenously with trastuzumab $24 \mathrm{~h}$ before administration of $\left({ }^{111} \mathrm{In}-\mathrm{DTPA}\right)_{\mathrm{n}}$-trastuzumab-(IRDye800 $)_{\mathrm{m}}$. Nonspecific uptake in the SKBr3-luc tumors was analyzed by injecting the mice with IRDye $800 \mathrm{CW}$ and $\left({ }^{111} \mathrm{In}-\mathrm{DTPA}\right)_{\mathrm{p}}$-IgG$(\text { IRDye800) })_{\text {, where " }} p$ " and " $q$ " are the stoichiometric ratios of DTPA and IRDye $800 \mathrm{CW}$ bound per IgG antibody, respectively. Results: (DTPA) -trastuzumab-(IRDye800) $_{m}$ showed significantly greater binding to SKBr3 cells than to MDA-MB-231 cells. Confocal imaging revealed that this binding occurred predominantly around the cell membrane. Competitive binding studies with excess trastuzumab before incubation with (DTPA) $)_{n}$-trastuzumab$(\text { IRDye800 })_{m}$ abolished this binding affinity, but pretreatment with nonspecific IgG did not alter binding. In vivo nuclear and optical imaging of SKBr3-luc xenografts injected with $\left({ }^{111} \mathrm{In}-\mathrm{DTPA}\right)_{\mathrm{n}}$ -

Received Mar. 28, 2007; revision accepted Jun. 14, 2007.

For correspondence or reprints contact: Eva M. Sevick-Muraca, One Baylor Plaza, BCM 360, Baylor College of Medicine, Houston, TX 77030.

E-mail: evas@bcm.edu

COPYRIGHT @ 2007 by the Society of Nuclear Medicine, Inc.
trastuzumab-(IRDye800) $)_{m}$ revealed significantly more uptake in the tumor region than in the contralateral muscle region. The tumorto-muscle ratio decreased in mice pretreated with trastuzumab and in mice injected with IRDye $800 \mathrm{CW}$ and $\left({ }^{111} \mathrm{In}-\mathrm{DTPA}\right)_{\mathrm{p}}$-IgG$($ IRDye800) . Ex vivo imaging of dissected organs confirmed these results. Finally, coregistration of histologic hematoxylin-eosin stains with autoradiography signals from tumor and muscle tissue slices indicated that $\left({ }^{111} \mathrm{In} \text {-DTPA }\right)_{\mathrm{n}}$-trastuzumab-(IRDye 800$)_{\mathrm{m}}$ bound only in tumor tissue and not to muscle. Conclusion: Dual-labeled $\left({ }^{111} \text { In-DTPA }\right)_{n}$-trastuzumab-(IRDye800 $)_{m}$ may be an effective diagnostic biomarker capable of tracking HER2 overexpression in breast cancer patients.

Key Words: dual labeling; trastuzumab; HER2 overexpression; breast cancer; near-infrared optical imaging

J Nucl Med 2007; 48:1501-1510

DOI: 10.2967/jnumed.107.042234

$\mathbf{M}$ olecular imaging agents that are dual labeled with nuclear and optical reporters provide unique opportunities for noninvasive diagnostic imaging with PET or SPECT radionuclides and for subsequent intraoperative guidance with near-infrared (NIR) fluorophores. Although NIR fluorescence and nuclear reporters possess comparable sensitivities for molecular imaging, each possesses complementary advantages that outweigh the other's limitations. For example, whereas NIR fluorophores might be expected to be limited in tissue penetration depth, nuclear reporters are not, and whereas nuclear reporters have a physical half-life that limits the period for imaging, NIR fluorescent agents have no physical half-life. Consequently, NIR imaging agents need to be based on biologic rather than both biologic and physical half-lives.

Recently, Houston et al. (1) used imaging with duallabeled RGD peptides against $\alpha_{v} \beta_{3}$ integrin expression in a subcutaneous xenograft model; they showed comparable optical planar imaging and scintigraphy results but enhanced signal-to-noise ratio with NIR fluorescence imaging relative to nuclear imaging. For subcutaneous xenograft models, which offer shallow penetration depths, these results might 
be expected and might be similar to what might be encountered in intraoperative guidance. In this work, we describe preclinical imaging with a dual-labeled antibody that is under development for noninvasive imaging and intraoperative identification of metastases in human epidermal growth factor receptor (HER)-positive breast cancer patients.

The second member of the HER family, HER2, is overexpressed in approximately $20 \%-30 \%$ of breast cancer patients (2). This overexpression is often associated with a poor prognosis. By blocking HER2 homo- or heterodimerization with HER1 and HER3, downstream proliferative signaling can be interrupted for a therapeutic advantage. Trastuzumab (Herceptin; Genentech Inc.) is a humanized anti-HER2 antibody (3) that interferes with HER2 signaling and is approved for therapeutic use in breast cancer $(4,5)$. Apart from being an excellent target for therapy, the extracellular domain of HER2 on the plasma membrane is also a potential target for diagnostic biomarkers. When HER 2 is expressed in primary breast lesions, it is also stably expressed in lymph node metastases and distant metastases $(6,7)$ and remains so throughout therapy, indicating a lack of sensitization of HER2 levels to therapy (8-10). The stability of HER2 expression with tumor progression and therapy and the availability of an antibody to target it suggest the use of HER2-targeted diagnostic imaging for nodal staging. Several investigators have labeled the intact and derived forms and fragments $\left[\mathrm{Fab}, \mathrm{F}\left(\mathrm{ab}^{\prime}\right)_{2}\right]$ of trastuzumab antibody with nuclear agents, including ${ }^{68} \mathrm{Ga}$ (11), ${ }^{90} \mathrm{Y}(12),{ }^{111} \mathrm{In}(12-14)$, and ${ }^{99 \mathrm{~m}} \mathrm{Tc}(15)$, and with a red fluorescent dye, Cy5.5 (16), to image HER2-overexpressing breast cancer xenografts. Other trastuzumab-based imaging methods or agents that have been reported include conjugation with quantum dots $(17,18)$, nanocrystals $(19)$, iron oxide (20), and gold nanoparticles (21) to detect cancer. Recently, ${ }^{111}$ In-labeled trastuzumab was clinically translated for scintigraphy to identify HER2-positive metastases (22).

In this study, we synthesized $\left({ }^{111} \mathrm{In}\right.$-diethylenetriaminepentaacetic acid [DTPA] $)_{n}$-trastuzumab-(IRDye800) ${ }_{m}$, a dually labeled conjugate that makes use of the following features: the stable emission of an NIR fluorescent dye, IRDye $800 \mathrm{CW}$, which has no finite half-life; the $\gamma$-emission of ${ }^{111}$ In for scintigraphy for sentinel lymph node mapping; and the opportunity to cross-validate NIR and nuclear imaging modalities. We validated the imaging conjugate by imaging standard animal models of subcutaneous HER2-positive human breast tumors after intravenous administration of the conjugate; we showed the ability to deliver the agent into the lymphatic system for clearance within $24 \mathrm{~h}$.

\section{MATERIALS AND METHODS}

Trastuzumab was purchased and stored at $4^{\circ} \mathrm{C}$. IRDye $800 \mathrm{CW}$ was provided by Li-Cor Biosciences, and DTPA dianhydride was purchased from Sigma-Aldrich. Human IgG was obtained from Invitrogen.

\section{Synthesis of (DTPA) $n$-Trastuzumab}

Trastuzumab was conjugated with DTPA by use of the protocol described by Tang et al. (13). In brief, trastuzumab was dissolved in aqueous $\mathrm{NaHCO}_{3}(50 \mathrm{mM}$, pH 8.0) at a concentration of $5 \mathrm{mg} / \mathrm{mL}$ and mixed with a 100 -fold molar excess of DTPA dianhydride. After constant stirring for $30 \mathrm{~min}$ at room temperature, the reaction mixture was purified from excess DTPA by passage through a Sephadex G-25 (bead diameter, 50-150 $\mu \mathrm{m}$; Sigma-Aldrich) minicolumn and elution with phosphate-buffered saline (PBS) $(\mathrm{pH}$ 7.4). The number of DTPA molecules per trastuzumab antibody molecule (n) was determined by mass spectrometry. The synthesized conjugate was analyzed on a model 4700 Proteomics Analyzer matrix-assisted laser desorption/ionization tandem time-of-flight (MALDI TOF/TOF) instrument (Applied Biosystems) with linear detection and 3,5-dimethoxy-4-hydroxy-transcinnamic acid (sinapinic acid) as a matrix.

\section{Synthesis of (DTPA) $\mathrm{n}$-Trastuzumab-(IRDye800) $\mathrm{m}$}

Conjugation with IRDye 800 was performed according to the IRDye 800 antibody labeling kit protocol from Li-Cor Biosci-

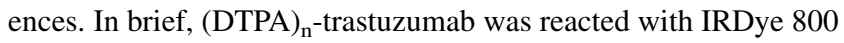
(dissolved in dimethyl sulfoxide [DMSO] [0.5 mg of dye $/ 25 \mu \mathrm{L}$ of DMSO]) at a mass ratio of 1:10 in PBS ( $\mathrm{pH} 7.4)$. The labeling reaction was performed in the dark at $4^{\circ} \mathrm{C}$ for $2 \mathrm{~h}$. To separate excess unreacted IRDye 800, dialysis was performed with PBS ( $\mathrm{pH}$ 7.4) for 16-24 h, with 3 buffer changes at regular intervals, by use of a Slide-A-Lyzer dialysis kit (Pierce) with a molecular weight cutoff of 10,000. Spectrophotometric (model DU-800 instrument; Beckman Coulter) analysis was used to determine the dye-toprotein ratio $(\mathrm{m})$ from absorbance values at 280 and $774 \mathrm{~nm}$ and to

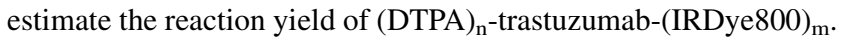

\section{Synthesis of (111/n-DTPA) -Trastuzumab-(IRDye800)}

${ }^{111} \mathrm{InCl}_{3}$ (in $0.05 \mathrm{M} \mathrm{HCl} ; 34.26 \mathrm{GBq} / \mathrm{mL}, 925.98 \mathrm{mCi} / \mathrm{mL}$ ) was obtained from Perkin-Elmer. ${ }^{111} \mathrm{InCl}_{3}$ with $0.1 \mathrm{~N}$ sodium acetate $\left(20 \mu \mathrm{L} / 37 \mathrm{MBq} \text { ) was added to (DTPA) } \text { }_{\mathrm{n}} \text {-trastuzumab-(IRDye } 800\right)_{\mathrm{m}}$ in PBS and mixed for $30 \mathrm{~min}$. Serum stability was assessed over a 24-h period after incubation of $\left({ }^{111} \text { In-DTPA }\right)_{n}$-trastuzumab(IRDye 800$)_{\mathrm{m}}$ in $1 \mathrm{~mL}$ of cell culture medium with $10 \%$ serum at $37^{\circ} \mathrm{C}$. High-performance liquid chromatography analysis with an Agilent 1100 series instrument (Agilent Technologies, Inc.) was used to monitor for degradation products.

The immunoreactive fraction of the dual-labeled trastuzumabbased imaging agent was determined by use of the assay described by Lindmo et al. (23). When SKBr3 human breast cancer cells reached $95 \%$ confluence in $10-\mathrm{cm}$ tissue culture dishes, they were treated with trypsin and washed with excess PBS. A 50-ng quantity of (In-DTPA) $)_{n}$-trastuzumab-(IRDye800) $)_{m}$ was added to increasing concentrations of SKBr3 cells $\left(0.2 \times 10^{6}-6 \times 10^{6}\right.$ cells per milliliter of cell culture medium). Uptake was determined after the cell suspensions were centrifuged and washed 3 times with PBS. Cells were suspended in $100 \mu \mathrm{L}$ of PBS and added to a microtiter plate, and the NIR fluorescence signal was obtained by use of an Odyssey infrared imaging system (Li-Cor Biosciences). The immunoreactive fraction was determined by plotting the fluorescence signal intensities versus increasing cell concentration. The maximum fluorescence intensity value was divided by the intensity arising from $50 \mathrm{ng}$ of (In-DTPA) $)_{\mathrm{n}}$-trastuzumab-(IRDye 800) $\mathrm{m}$ added to 100 $\mu \mathrm{L}$ of PBS.

\section{Synthesis of $\left({ }^{111} \ln -D T P A\right)_{p}$-IgG-(IRDye800)}

Human IgG was dual labeled with the DTPA chelating agent and IRDye 800 in a manner similar to that described previously for trastuzumab. The number of DTPA chelating molecules (p) 
was determined by mass spectrometry, and the dye-to-antibody ratio (q) was calculated by spectrophotometric analysis.

\section{Cell Lines}

Human breast cancer cells that express high levels of HER2 (SKBr3) and human breast cancer cells that express negligible levels of HER2 (MDA-MB-231) were used to conduct in vitro experiments. For in vivo imaging of HER2 receptor levels in tumor xenografts, we used a derivative SKBr3-luc cell line (provided by Michael Barry, Mayo Clinic) that had been incorporated with the firefly luciferase gene to aid in the monitoring of tumor growth by bioluminescence imaging. The cells were cultured in Dulbecco minimal essential medium-F-12 medium (Invitrogen) with $10 \%$ fetal bovine serum (Hyclone) in a humidified incubator maintained at $37^{\circ} \mathrm{C}$ with $5 \% \mathrm{CO}_{2}$.

\section{In Vitro Binding Studies}

When the cells reached $95 \%$ confluence in $10-\mathrm{cm}$ tissue culture dishes, they were treated with trypsin, washed with excess PBS, and resuspended in $100 \mu \mathrm{L}$ of culture medium with IRDye $800 \mathrm{CW}$ $(1 \mu \mathrm{M})$ or $(\text { DTPA })_{\mathrm{n}}$-trastuzumab-(IRDye 800$)_{\mathrm{m}}(0.1 \mu \mathrm{M}, \mathrm{m}=$ 9.15; equivalent to $1 \mu \mathrm{M}$ IRDye $800 \mathrm{CW}$ ). For competitive binding studies, SKBr3 cells were pretreated with trastuzumab $(22 \mu \mathrm{M})$ or human $\operatorname{IgG}(22 \mu \mathrm{M})$ for $30 \mathrm{~min}$ at $37^{\circ} \mathrm{C}$ and then treated with (DTPA) $)_{\mathrm{n}}$-trastuzumab-(IRDye 800$)_{\mathrm{m}}$ for $1 \mathrm{~h}$ at $37^{\circ} \mathrm{C}$. At the end of this incubation period, the cells were washed twice with PBS and incubated in a solution of Sytox Green in $95 \%$ ethanol $(1 \mu \mathrm{M}$; Molecular Probes) for $15 \mathrm{~min}$ to fix and stain cell nuclei.

\section{In Vitro Microscopy}

All images from the cell binding studies were recorded by use of a Leica fluorescence microscope (model DM6000 B; Leica Microsystems $\mathrm{GmbH}$ ) equipped with a 100-W xenon lamp and fluorescence filters. Confocal images of SKBr3 cells were obtained by use of an Olympus confocal microscope outfitted with NIR diode sources and filters (FluoView 1000; Olympus America).

\section{Tumor Xenografts}

Female athymic nude mice (3-4 wk old, 18-22 g; Harlan Sprague-Dawley, Inc.) were housed 5 per cage and provided with sterilized pellet chow and sterilized water. Animals were maintained in a pathogen-free mouse colony at the Frensley Center of Imaging Research at Baylor College of Medicine. The facility is accredited by the American Association for Laboratory Animal Care, and all experiments were performed in accordance with the guidelines of Baylor College of Medicine Institutional Animal Care and Use Committee. SKBr3-luc cells were treated with trypsin when near confluence and harvested. Cells were pelleted by centrifugation at 1,200 rpm for $5 \mathrm{~min}$ and resuspended in sterile culture medium. SKBr3-luc cells $\left(2 \times 10^{6}-3 \times 10^{6}\right.$ per animal $)$ were implanted subcutaneously into the left flank of the mice. Initial tumor growth was monitored by bioluminescence imaging. Nuclear and optical imaging was performed once the tumors reached $0.5-$ $0.8 \mathrm{~cm}$ in diameter.

\section{In Vivo Bioluminescence Imaging}

Athymic mice inoculated subcutaneously with SKBr3-luc cells were monitored for tumor growth by bioluminescence imaging. Mice were injected intraperitoneally with $100 \mu \mathrm{L}$ of $1 \mathrm{mM}$ D-luciferin (Marker Gene Technologies Inc.) 5 min before imaging. To capture the photons that are emitted after the reaction between luciferin and luciferase, we have designed an imaging system that consists of a light-tight imaging chamber (UVP) fitted with an electron-multiplying charge-coupled device (EMCCD) camera (model PhotoMAX:512B; Princeton Instruments). Image acquisition was accomplished with $\mathrm{V}++$ software (Digital Optics). Data processing and analysis were accomplished with Image $\mathbf{J}$ software (National Institutes of Health). The integration time for whitelight photographic images was $800 \mathrm{~ms}$, whereas bioluminescence images were acquired after integration for $5 \mathrm{~min}$. The images were overlaid to verify the location of the tumor.

\section{In Vivo Fluorescence Imaging}

In vivo fluorescence imaging was accomplished by illuminating the animal with light from a laser diode $(85 \mathrm{~mA}$ and $80 \mathrm{~mW}$ for 785-nm light; DL7140-201; Sanyo) that expanded to a circular area approximately $8 \mathrm{~cm}$ in diameter. The reemitted fluorescent light was collected with an EMCCD camera. Filter sets used in this study included a band-pass filter with an 830-nm center wavelength and an optical density of greater than 3 at $785 \mathrm{~nm}$ (ANDV8483; Andover Corp.) for collecting IRDye $800 \mathrm{CW}$ fluorescence and a holographic filter with an optical density of greater than 6 (HSP 785.0; Kaiser Optical Systems) for rejecting backscattered and reflected excitation light. Image acquisition was accomplished with $\mathrm{V}++$ software, and data processing and analysis were accomplished with Image $\mathbf{J}$ software. The integration time for white-light and fluorescence images was $800 \mathrm{~ms}$.

Whole-body fluorescence images were obtained 24 and $48 \mathrm{~h}$ after intravenous injection of $\left({ }^{111} \text { In-DTPA }\right)_{n}$-trastuzumab$(\text { IRDye } 800)_{\mathrm{m}}(0.43 \mathrm{nmol}, 80 \mu \mathrm{g}, \mathrm{m}=7.6),\left({ }^{111} \mathrm{In}-\mathrm{DTPA}\right)_{\mathrm{p}}$-IgG$(\text { IRDye } 800)_{\mathrm{q}}(0.53 \mathrm{nmol}, 80 \mu \mathrm{g}, \mathrm{q}=3)$, and free IRDye $800 \mathrm{CW}$ $(3.28 \mathrm{nmol}, 3.8 \mu \mathrm{g})$. For competitive binding studies, animals were preinjected with a 200 -fold molar excess of trastuzumab $(86 \mathrm{nmol}$, $16 \mathrm{mg}) 24 \mathrm{~h}$ before the administration of $\left({ }^{111} \mathrm{In} \text {-DTPA }\right)_{\mathrm{n}}$-trastuzumab-(IRDye 800$)_{\mathrm{m}}$. At various time points, mice were sacrificed, and images of the excised organs were obtained. For quantitative comparisons, ratios of fluorescence signal intensities in the regions of interest (ROIs) corresponding to the tumor and normal tissue regions were determined.

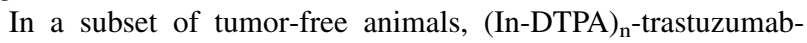
$(\text { IRDye } 800)_{\mathrm{m}}(16 \mathrm{pmol}, 3 \mu \mathrm{g}, \mathrm{m}=7.6)$ was administered intradermally into the footpad with a MicroCone catheter (BD Technologies). NIR fluorescence imaging was performed immediately and at $24 \mathrm{~h}$ to visualize the lymphatic delivery of the agent to the popliteal lymph nodes and its subsequent clearance.

\section{Small-Animal SPECT/CT}

SPECT and CT images were acquired consecutively with a MicroCAT II scanner (Siemens Medical Solutions) $48 \mathrm{~h}$ after injection of ( $\left.{ }^{111} \mathrm{In}-\mathrm{DTPA}\right)_{\mathrm{n}}$-trastuzumab-(IRDye 800$)_{\mathrm{m}}(1 \mathrm{nmol}$, $200 \mu \mathrm{g}, 7.4 \mathrm{MBq}$ ) into SKBr3-luc xenografts. The SPECT scan was acquired for 20 projections over $360^{\circ}$ for a scan time of $1 \mathrm{~min}$ per frame. SPECT and CT tomographic images were coregistered by geometric transformation and rendered to make the fused images with Amira (version 3.1; Konrad-Zuse-Zentrum fur Informationstechnik). Planar scintigraphy was performed $24 \mathrm{~h}$ after the mice were injected with $\left({ }^{111} \text { In-DTPA) }\right)_{\mathrm{n}}$-trastuzumab-(IRDye 800$)_{\mathrm{m}}$ (0.22 nmol, $40 \mu \mathrm{g}, \sim 2.8 \mathrm{MBq}$ ) by removing the 3-mm pinhole collimator of the SPECT scanner, adding a $1.22-\mathrm{mm}$ planar collimator, and integrating for $10 \mathrm{~min}$.

Scintillation counts per minute from excised organs of SKBr3-luc tumor-bearing mice preinjected with $\left({ }^{111} \mathrm{In} \text {-DTPA }\right)_{\mathrm{n}}$-trastuzumab-

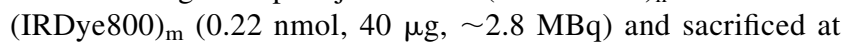
various time points were acquired with a MicroBeta TriLux 
(Perkin-Elmer) detection system. The integration time used for acquisition ranged from 1 to $3 \mathrm{~min}$.

\section{Autoradiography and Histologic Staining}

Frozen sections of tissue slices from the tumor region were prepared to correlate the radioactive signal obtained from $\left({ }^{111} \mathrm{In}\right.$ -

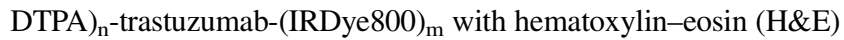
staining to demonstrate the stability and specificity of the dye conjugate.

\section{Statistical Analysis}

Statistical analysis was performed with SAS software (version 9.1; SAS Institute Inc.) for Microsoft Windows. The data were analyzed with one-way analysis of variance and general linear models. The significance level was set at 0.05 , and statistical analysis of the tumor-to-muscle ratio (TMR) was performed with fluorescence images obtained at various time points. In this study, TMR was calculated as follows:

$\mathrm{TMR}=($ sum of fluorescence counts in tumor region/number of pixels)/(sum of fluorescence counts in muscle region/number of pixels).

Eq. 1

To determine TMR from whole-body fluorescence images, an ROI was drawn around the tumor region, and the total fluorescence signal intensity associated with the region was computed. For in vivo analysis, the same ROI was used for the contralateral muscle to compute the fluorescence signal intensity.

In excised tissue, TMR was computed by determining the total fluorescence signal intensity observed in the tumor and muscle regions by drawing an ROI around each tissue independently. Because Equation 1 includes normalization by area or number of pixels, it was used to compute TMR in excised tissue.

To calculate TMR from SPECT/CT images, tumor volume was computed from the SPECT data, and the signal intensities were recorded. The same volume was used to compute the signal intensity from the muscle region. Analysis of TMR was done with Inveon Research Workplace (Siemens Medical Solutions).
TMR for scintillation counts obtained from excised tissue was computed with the following equation:

TMR $=($ scintillation counts per minute in tumor region/gram of tumor)/(scintillation counts per minute in muscle region/gram of muscle).

Eq. 2

\section{RESULTS}

\section{Synthesis and Characterization of $\left({ }^{111} \mathrm{In}-\mathrm{DTPA}\right)_{\mathrm{n}}$ - Trastuzumab-(IRDye800) $)_{m}$}

Mass spectrometry determined that the number of DTPA molecules conjugated with trastuzumab was 10 . The yield was typically $98 \%$. The absorption and fluorescence emission characteristics of ( ${ }^{111}$ In-DTPA $)_{n}$-trastuzumab(IRDye800) $)_{\mathrm{m}}$ were similar to those of free IRDye $800 \mathrm{CW}$ when measured in the spectrophotometer (data not shown for brevity). This finding suggests that the fluorescence properties of IRDye $800 \mathrm{CW}$ were not altered on conjugation with the antibody. The molar ratio of IRDye 800 to trastuzumab was between 7 and 10 . The yield was typically $90 \%$. Although $\left({ }^{111} \mathrm{In}-\mathrm{DTPA}\right)_{\mathrm{n}}$-trastuzumab-(IRDye 800$)_{\mathrm{m}}$ is stable at $4^{\circ} \mathrm{C}$ over $14 \mathrm{~d}$, serum-based degradation of the agent at $37^{\circ} \mathrm{C}$ was determined from high-performance liquid chromatography to be approximately $6 \% / \mathrm{d}$. The immunoreactive fraction estimated by the assay of Lindmo et al. (23) was found to be 0.95 .

\section{Synthesis and Characterization of $\left({ }^{111} \ln -D T P A\right)_{p}-\lg G-$ (IRDye800) $q$}

Human IgG was conjugated with ${ }^{111}$ In and IRDye $800 \mathrm{CW}$ in a procedure similar to that outlined for trastuzumab. Because IRDye $800 \mathrm{CW}$ binds to the lysine residues on the antibody, we would expect a range of dye-to-protein ratios like those obtained for trastuzumab. For the single batch
FIGURE 1. (A and B) Fluorescence microscopy imaging shows significant binding of (DTPA) $)_{n}$-trastuzumab-(IRDye800 $)_{m}$ in HER2-overexpressing SKBr3 cells $(A)$ in comparison with MDA-MB-231 cells, which express low levels of HER2 (B). Reduction in apparent "brightness" arises because of overlay of red and green channels when agent binding occurs. (C) Confocal imaging of SKBr3 cells incubated with imaging agent reveals extracellular membrane binding. (D) Magnified view of representative cell. (E and F) Pretreatment with trastuzumab significantly reduced binding of imaging agent by competition $(E)$, whereas pretreatment of cells with human IgG did not alter binding of imaging agent significantly $(F)$. (G) IRDye $800 \mathrm{CW}$ did not exhibit nonspe-

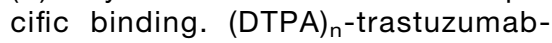
$(\text { IRDye } 800)_{m}$ is represented in red, whereas cell nuclei stained with Sytox Green are represented in green.

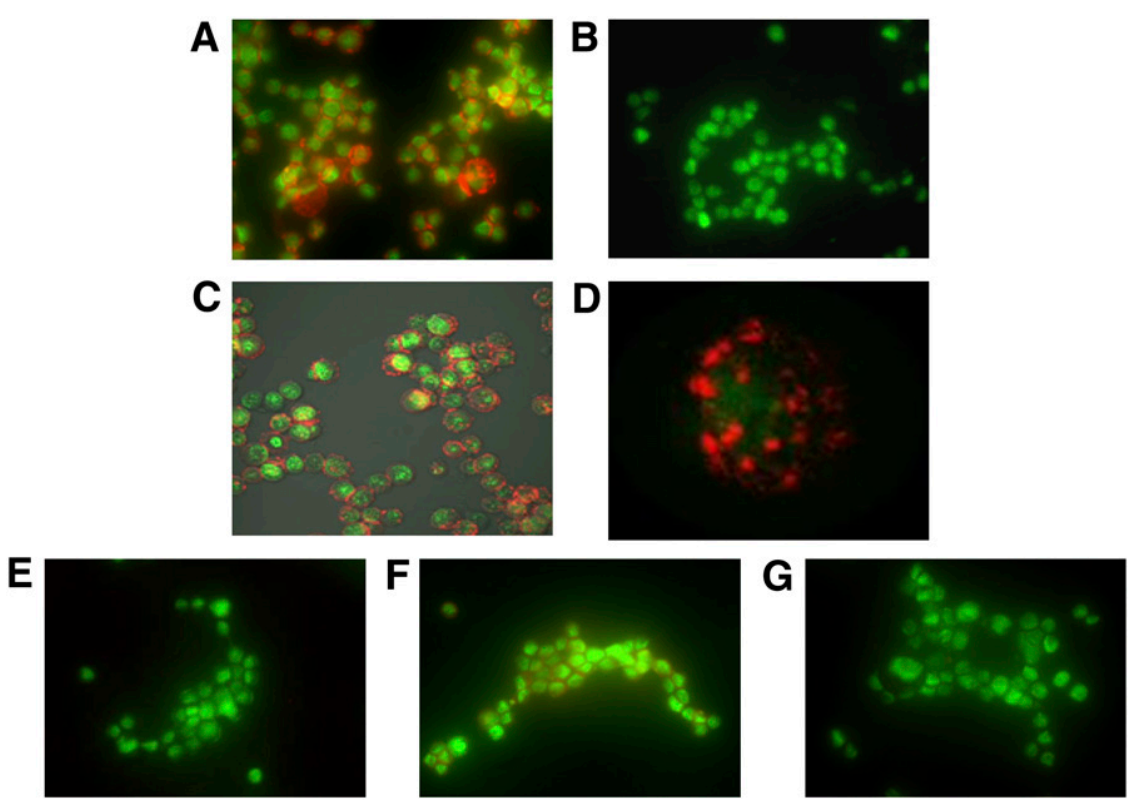


of $\left({ }^{111} \mathrm{In}-\mathrm{DTPA}\right)_{\mathrm{p}}$-IgG-(IRDye800 $)_{\mathrm{q}}$, the molar ratio of IRDye 800 to $\operatorname{IgG}(\mathrm{q})$ was approximately 3 , and the yield was $90 \%$.

\section{In Vitro Binding Studies}

Figure 1 compares the fluorescence images of SKBr3 cells (overexpressing HER2) and MDA-MB-231 cells (expressing

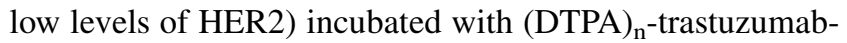
(IRDye800) $)_{\mathrm{m}}$. The imaging agent bound with high specificity to SKBr3 cells but not to MDA-MB-231 cells (Figs. 1A and $1 \mathrm{~B})$. Confocal microscopy imaging of SKBr3 cells confirmed that the agent bound to the extracellular domain of the cells (Fig. 1C) and appeared as spots or clusters on the surface membrane, as shown by a higher magnification (Fig. 1D). Fur-

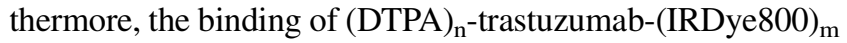
was abolished when SKBr3 cells were pretreated with a 200fold molar excess of trastuzumab (Fig. 1E) but not when the cells were pretreated with the same amount of nonspecific human $\operatorname{IgG}$ (Fig. 1F). As a measure of control to ensure the absence of nonspecific binding, SKBr3 cells incubated with an equivalent dose of free IRDye $800 \mathrm{CW}$ showed negligible binding (Fig. 1G).

\section{In Vivo Nuclear and Optical Imaging}

Figure 2 shows a series of whole-body fluorescence images of mice inoculated with SKBr3-luc tumors; the images were obtained $48 \mathrm{~h}$ after the administration of $\left({ }^{111} \mathrm{In}-\mathrm{DTPA}\right)_{\mathrm{n}^{-}}$

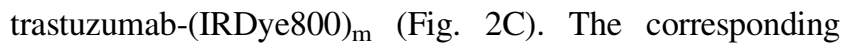
white-light image is shown in Figure 2B. A bioluminescence image was overlaid on a white-light image for easy identification of the tumor location (Fig. 2A). The fluorescence signal intensities observed in the tumor region of these mice were significantly higher than those in the rest of the body.

Three standard tubes were placed beside each mouse during fluorescence imaging. These included ( $\left.{ }^{111} \mathrm{In}-\mathrm{DTPA}\right)_{\mathrm{n}^{-}}$ trastuzumab-(IRDye800) $)_{\mathrm{m}}(5.44 \mathrm{mM}$; dye equivalent, 0.22 $\mu \mathrm{M})$ (Fig. 2B, location 1), $\left({ }^{11} \text { In-DTPA) }\right)_{\mathrm{p}}$-IgG-(IRDye 800$)_{\mathrm{q}}$ (6.35 mM; dye equivalent, $0.12 \mu \mathrm{M}$ ) (Fig. 2B, location 2), and IRDye $800 \mathrm{CW}(0.16 \mu \mathrm{M})$ (Fig. 2B, location 3$)$. In vivo blocking studies indicated a decrease in fluorescence signal intensity in the tumor region and an increase in the liver in
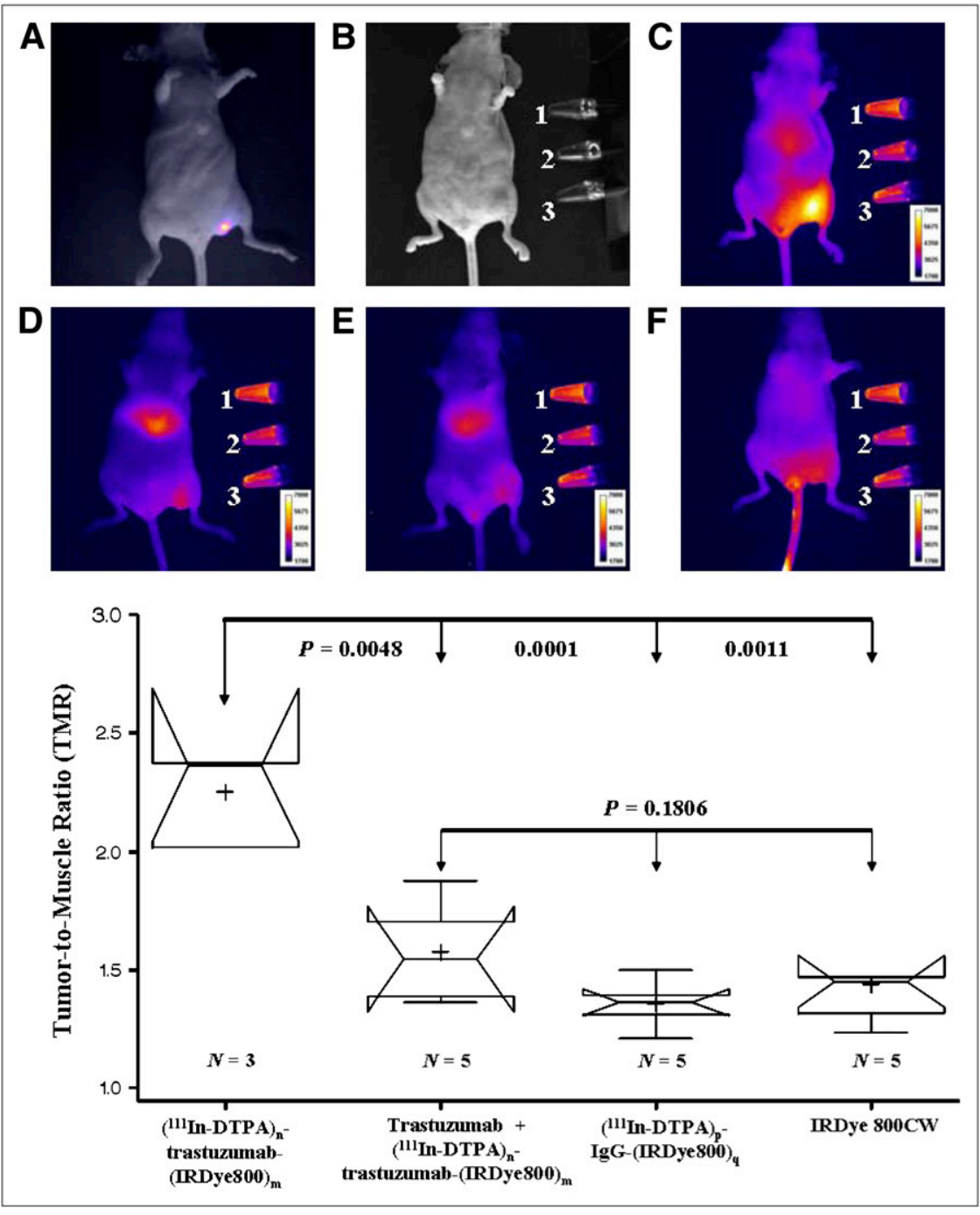

FIGURE 2. SKBr3-luc cancer cells were inoculated into left flank of athymic nu/nu mice. (A) Bioluminescence image overlaid on white-light image helps confirm presence of SKBr3-luc tumor xenograft near left flank of nu/nu mouse. (B-F) White-light image (B) of mouse taken before fluorescence imaging of $\left({ }^{111} \mathrm{In}\right.$ DTPA) -trastuzumab-(IRDye800) $_{m}$ (C), 200-fold molar excess of trastuzumab followed by ( ${ }^{111}$ In-DTPA $)_{n}$-trastuzumab$(\text { IRDye800 })_{m}$ (D), $\quad\left({ }^{111} \text { In-DTPA }\right)_{\mathrm{p}}$-IgG$(\text { IRDye800) })_{\mathrm{q}}(\mathrm{E})$, or equivalent dose of IRDye 800CW (F) $48 \mathrm{~h}$ after administration. Standards placed on side include $\left({ }^{111} \text { In-DTPA }\right)_{n}$-trastuzumab-(IRDye800 $)_{m}$ (1), $\left({ }^{111} \ln -D T P A\right)_{p}-$ IgG-(IRDye800) $q$ (2), and IRDye $800 \mathrm{CW}$ (3). Notched box-andwhisker statistical comparisons of TMRs among 4 groups are also shown. Mice injected with ( ${ }^{111} / \mathrm{n}$-DTPA $)_{\mathrm{n}}$-trastuzumab(IRDye800) ${ }_{m}$ had significantly higher TMRs than all other groups - trastuzumab followed by $\left({ }^{111} \mathrm{In}-\mathrm{DTPA}\right)_{\mathrm{n}}$-trastuzumab-(IRDye800 $)_{m}(P=0.0048),\left({ }^{111} / \mathrm{n}-\mathrm{DTPA}\right)_{\mathrm{p}^{-}}$ IgG-(IRDye800 $)_{\mathrm{q}}(P=0.0001)$, and IRDye $800 \mathrm{CW}(P=0.0011)$. However, difference between preblocking with trastuzumab and treatment with nonspecific $\left({ }^{111} \text { In-DTPA) }\right)_{p}$-IgG-(IRDye800) or IRDye $800 \mathrm{CW}$ was not statistically significant $(P=0.1806)$. 
mice that were preinjected with trastuzumab $24 \mathrm{~h}$ before the administration of ( $\left.{ }^{111} \mathrm{In}-\mathrm{DTPA}\right)_{\mathrm{n}}$-trastuzumab-(IRDye 800$)_{\mathrm{m}}$ (Fig. 2D). The increase may have occurred because of the reduction of specific binding sites for $\left({ }^{111} \mathrm{In}-\mathrm{DTPA}\right)_{\mathrm{n}^{-}}$ trastuzumab-(IRDye800) $\mathrm{m}$, which may have been occupied by trastuzumab. Nonspecific ( ${ }^{111}$ In-DTPA) $)_{\mathrm{p}}$-IgG-(IRDye 800$)_{\mathrm{q}}$ and IRDye $800 \mathrm{CW}$ appeared to show some uptake in the tumor region (Figs. $2 \mathrm{E}$ and $2 \mathrm{~F}$ ), but this uptake was significantly lower than that seen after the administration of ( ${ }^{111}$ In-DTPA $)_{n^{-}}$ trastuzumab-(IRDye800) m $_{\mathrm{m}}$.

A quantitative analysis of the in vivo whole-body fluorescence imaging data is represented by the notched box-andwhisker plots in Figure 2. The statistical results demonstrated that the dual-labeled agent, ( ${ }^{111}$ In-DTPA) $)_{n}$-trastuzumab(IRDye800) $)_{\mathrm{m}}$, had the highest TMR $(2.25 \pm 0.2)$ when compared with $\left({ }^{111} \text { In-DTPA) }\right)_{\mathrm{p}}$-IgG-(IRDye 800$)_{\mathrm{q}}(1.35 \pm 0.1)$ and IRDye $800 \mathrm{CW}(1.44 \pm 0.18)$, indicating its superior specificity in binding to HER2-overexpressing SKBr3-luc xenografts. The TMR for mice preinjected with trastuzumab was significantly lower than that for the control $(P=0.0048)$ but was not statistically different from those obtained with $\left({ }^{111} \text { In-DTPA }\right)_{\mathrm{p}}$-IgG-(IRDye 800$)_{\mathrm{q}}$ and IRDye $800 \mathrm{CW}(P=$ $0.1806)$. The decrease in signal intensity after pretreatment was attributable to the decrease in the number of unbound receptors.

SPECT also revealed significant uptake of $\left({ }^{111} \mathrm{In}-\mathrm{DTPA}\right)_{\mathrm{n}^{-}}$ trastuzumab-(IRDye800) $)_{\mathrm{m}}$ in the tumor region compared with the muscle region (Fig. 3A). The observed TMR was 2.66. Whole-body planar scintigraphy images also indicated significant uptake in the tumor region (Fig. 3B), with a TMR of 2.17 .

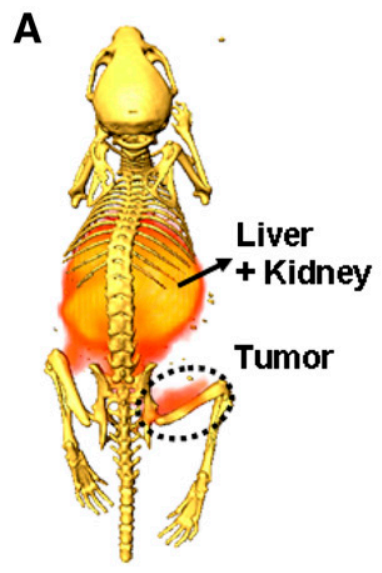

B

FIGURE 3. (A) Three-dimensional SPECT integrated for 20 min shows accumulation of dually labeled $\left({ }^{111} \mathrm{In}-\mathrm{DTPA}\right)_{\mathrm{n}^{-}}$ trastuzumab-(IRDye800) $\mathrm{m}(1 \mathrm{nmol}, 200 \mu \mathrm{g}, 7.4 \mathrm{MBq})$ in SKBr3-luc xenograft after $48 \mathrm{~h}$. (B) Two-dimensional scintigraphy was performed $24 \mathrm{~h}$ after injection of $\left({ }^{111} \text { In-DTPA }\right)_{n^{-}}$ trastuzumab-(IRDye 800$)_{\mathrm{m}}(0.22 \mathrm{nmol}, 40 \mu \mathrm{g}, \sim 2.8 \mathrm{MBq})$ and integration for $10 \mathrm{~min}$. These experiments were performed on different mice.

\section{Ex Vivo Nuclear and Optical Imaging}

Dissection of major organs $48 \mathrm{~h}$ after injection of the imaging agents confirmed that the fluorescence signal intensities observed in the chest and pelvic regions of the mouse, in addition to the tumor region, were mainly attributable to the liver and kidneys. The liver region exhibited significant fluorescence activity in the mice injected with the antibody-based imaging agents (trastuzumab and $\operatorname{IgG}$ ) (Figs. 4B-4D). The high liver uptake can be attributed to the interaction of the $\mathrm{Fc}$ receptors present on the antibody with hepatocytes, whereas the fluorescence signal intensities in the kidneys reflect the clearance of IRDye $800 \mathrm{CW}$ after degradation in the liver. In contrast, mice injected with free IRDye $800 \mathrm{CW}$ did not show accumulation in the liver (Fig. $4 \mathrm{E})$ but rather showed clearance through the kidneys. Excised tumor tissue had a significantly higher fluorescence signal intensity than muscle in each of the 4 groups, but the TMR for mice treated with $\left({ }^{111} \text { In-DTPA }\right)_{n}$-trastuzumab(IRDye 800$)_{\mathrm{m}}$ was statistically higher than that for mice treated with nonspecific $\left({ }^{111} \text { In-DTPA }\right)_{\mathrm{p}}$-IgG-(IRDye 800$)_{\mathrm{q}}$ and free IRDye $800 \mathrm{CW}(P=0.0304$ and $P=0.0482$, respectively). These results are consistent with what was observed with in vivo imaging. Moreover, pretreatment with trastuzumab reduced the binding affinity of $\left({ }^{111} \text { In-DTPA }\right)_{n^{-}}$ trastuzumab-(IRDye 800$)_{\mathrm{m}}$ significantly $(P=0.0354)$.

Figure 5A compares the ex vivo TMRs between nuclear and optical modalities at various time points after intravenous administration of ( ${ }^{111}$ In-DTPA $)_{n}$-trastuzumab-(IRDye 800$)_{m}$. No statistically significant differences between the TMRs were observed between time points within each modality, but the TMRs observed with optical imaging were statistically higher compared to observed with nuclear imaging $(P<$ $0.0001)$ at each time point. This result was expected because the TMRs computed for optical imaging were normalized by area (or pixel number), whereas those computed for nuclear imaging were normalized by tissue weight. An $R$ value of 0.9476 suggests a statistically high $(P<0.0001)$ degree of correlation between the optical imaging and nuclear imaging TMRs (Fig. 5B), as would be expected for a dual-labeled imaging agent. When TMRs were reported on a consistent basis (i.e., tissue weight), the statistical differences between optical imaging and nuclear imaging TMRs were lost, as shown in Figure 5C. In addition, when the TMRs were reported on a consistent basis, the SE bars for optical imaging were smaller than those for nuclear imaging, a result that we previously reported for a dual-labeled peptide agent (1). Besides the tumor and muscle tissues, we conducted similar preliminary biodistribution studies of other excised tissues and found that although there was a one-to-one correspondence of organ-to-muscle ratios from optical and nuclear signals, the routes for clearance, namely, the kidneys and bladder, exhibited statistically significant differences in the ratios derived from IRDye 800 and ${ }^{111} \mathrm{In}$. Although preliminary, these results indicate differences in the clearance and degradation of IRDye 800 and ${ }^{111}$ In-DTPA $48 \mathrm{~h}$ after 


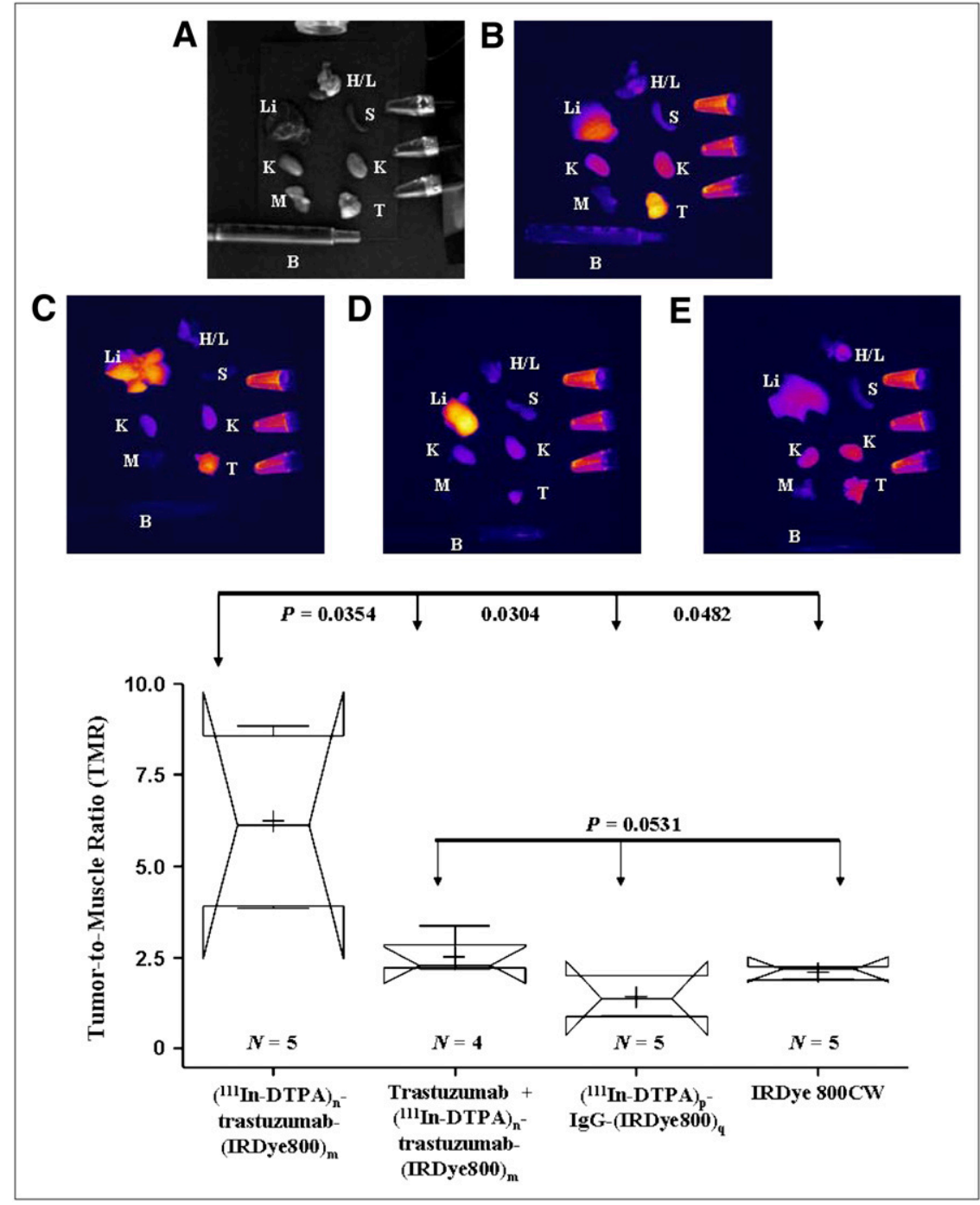

FIGURE 4. (A-E) White-light image (A) and ex vivo organ images of mice sacrificed $48 \mathrm{~h}$ after injection with $\left({ }^{111} \mathrm{In}\right.$ DTPA) ${ }_{n}$-trastuzumab-(IRDye800) ${ }_{m}$ (B), trastuzumab followed by $\left({ }^{111} \mathrm{In}-\mathrm{DTPA}\right)_{\mathrm{n}}$ trastuzumab-(IRDye800) $)_{m}$ (C), $\left({ }^{111}\right.$ InDTPA) $)_{p}$-IgG-(IRDye800) $($ (D), or equivalent dose of IRDye $800 \mathrm{CW}(\mathrm{E})$. Tissues dissected include heart and lungs $(H / L)$, liver $(\mathrm{Li})$, spleen (S), kidneys (K), muscle $(\mathrm{M})$, tumor $(\mathrm{T})$, and blood (B). Notched boxand-whisker statistical comparisons of TMR among 4 groups are also shown. TMRs were calculated by marking ROls around tumor and muscle tissues that had been dissected and measuring fluorescence signal intensities. Mice injected with $\left({ }^{111} \mathrm{In} \text {-DTPA }\right)_{n}$-trastuzumab(IRDye 800$)_{m}$ had significantly higher TMRs than all other groups - trastuzumab followed by $\left({ }^{111} \mathrm{In} \text {-DTPA) }\right)_{n}$-trastuzumab$(\text { IRDye800 })_{m}(P=0.0354),\left({ }^{111} \text { In-DTPA }\right)_{p^{-}}$ IgG-(IRDye800 $)_{\mathrm{q}}(P=0.0304)$, and IRDye 800CW ( $P=0.0482)$. However, difference between preblocking with trastuzumab and treatment with nonspecific $\left({ }^{111} \mathrm{In}-\mathrm{DTPA}\right)_{\mathrm{p}}$-IgG-(IRDye800) $)_{\mathrm{q}}$ or IRDye $800 \mathrm{CW}$ was not statistically significant $(P=0.0531)$. processing in the liver, where antibody or agent degradation occurs.

To determine the specificity of the trastuzumab-based imaging agent at a molecular level, 5- $\mu \mathrm{m}$ tissue slices from the tumor region of mice injected with $\left({ }^{111} \text { In-DTPA }\right)_{n^{-}}$ trastuzumab-(IRDye800) $\mathrm{m}$ were obtained $48 \mathrm{~h}$ after agent administration. Autoradiography was performed on these slices because of the presence of ${ }^{111}$ In (Fig. 6A). H\&E staining was performed subsequently on the same slices to show tumor morphology (Fig. 6B). By overlaying the autoradiography signal on $\mathrm{H} \& \mathrm{E}$ staining, we were able to determine the locations of uptake of $\left({ }^{111} \text { In-DTPA }\right)_{n}$-trastuzumab$(\text { IRDye800) })_{\mathrm{m}}$ in the tissues (Fig. 6C). Our results indicated that the imaging agent showed specific uptake in the tumor region.

Autoradiography signals and H\&E staining were also analyzed for the liver, kidneys, and muscle (data not shown). Autoradiography signals from the liver and kidneys were consistent with the fluorescence observed with both in vivo imaging and ex vivo imaging, but $H \& E$ staining revealed no aberrant pathology in these tissues, indicating liverspecific antibody uptake and clearance of degraded fragments through the kidneys. Muscle showed negligible radioactivity, a result that is consistent with data obtained from fluorescence imaging and SPECT.

Figure 7 depicts a typical image of a tumor-free athymic mouse after intradermal delivery of (In-DTPA) $n^{-}$ trastuzumab-(IRDye800) $\mathrm{m}$. The results indicated immediate uptake of the agent into the lymphatic channels that drain into the popliteal nodes (Fig. 7B). An alternate view of the same mouse is shown in Figure 7C. Within $24 \mathrm{~h}$, the agent was cleared from the lymph nodes, and the signal intensity at the injection site was dramatically reduced (Fig. 7D). The accumulation of the agent in the liver after $24 \mathrm{~h}$ is consistent with the mode of antibody degradation and clearance illustrated by the in vivo imaging data. Nuclear imaging was not performed because of the inability to distinguish between low signal counts at the time of imaging and actual clearance. 

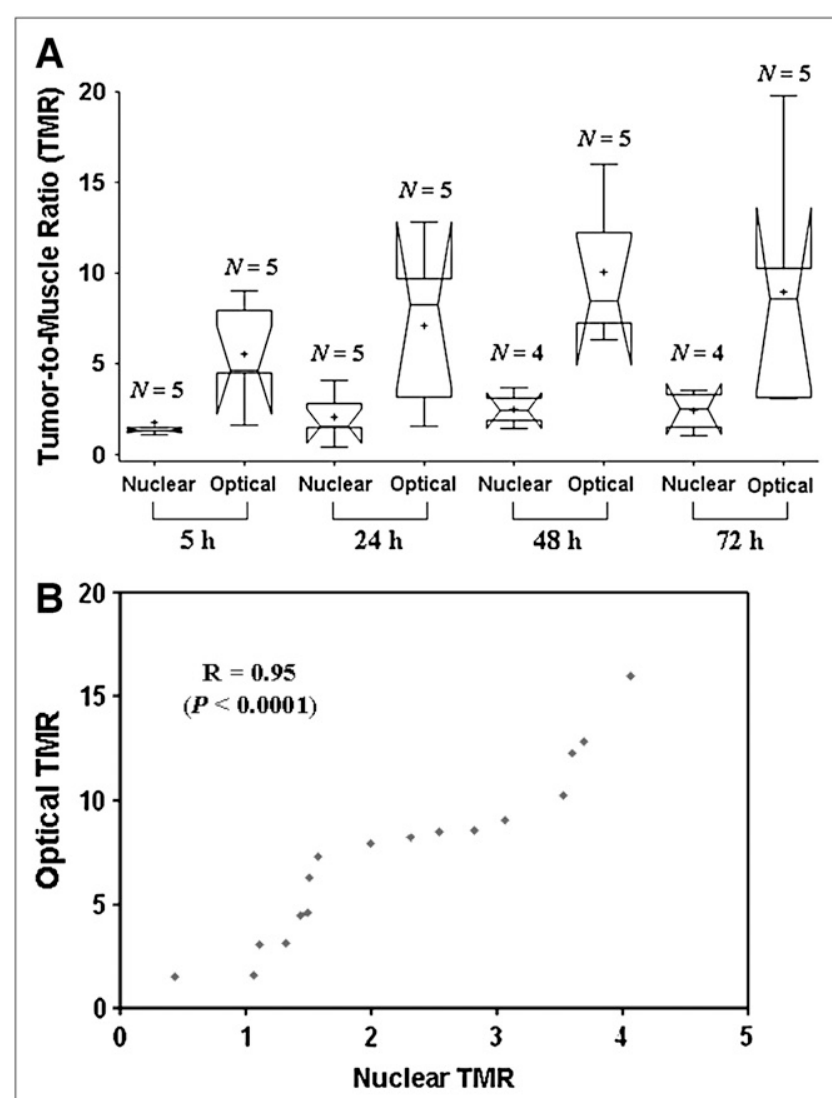

C

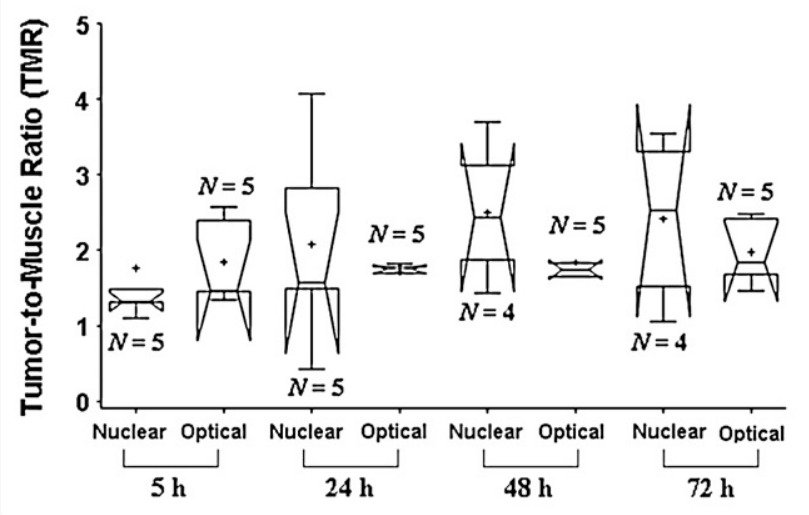

FIGURE 5. Athymic mice bearing SKBr3-luc xenografts were sacrificed at $5,24,48$, and $72 \mathrm{~h}$ after intravenous injection of $\left({ }^{111} \mathrm{In} \text {-DTPA }\right)_{\mathrm{n}}$-trastuzumab-(IRDye800) $)_{\mathrm{m}}$, and major organs were dissected. (A) Notched box-and-whisker statistical plots compare TMRs obtained with $\gamma$-scintillation counting for nuclear counts and NIR fluorescence imaging for optical counts at various time points. There was no statistical significance in TMRs observed at various time points within each imaging modality, but TMRs obtained with optical imaging were statistically higher than those obtained with nuclear imaging $(P<$ 0.0001 ) at each time point. (B) Plots of nuclear versus optical TMRs obtained with nuclear imaging and optical imaging for these mice yielded an $R$ value of $0.9476(P<0.0001)$, suggesting that results obtained from nuclear imaging and optical imaging are highly correlated. (C) When TMRs were compared on a consistent basis with respect to tissue weight (g), the statistical differences between optical and nuclear imaging are abolished.

\section{DISCUSSION}

The first human uses of trastuzumab administered systemically as an imaging agent were reported by Behr et al. (24) and Lub-de Hooge et al. (25). After preclinical work showing targeting capabilities (25), Lub-de Hooge et al. recently administered ${ }^{111}$ In-DTPA-trastuzumab systemically in patients with HER2-overexpressing metastatic breast cancer (25). In 13 of the 15 patients, late-stage metastases that were not previously identified were identified by SPECT/CT.

However, to date, diagnostic imaging for early-stage metastases has not involved molecular imaging approaches. Typically, early nodal staging is performed with intradermal and subcutaneous administration of nonspecific ${ }^{99 \mathrm{~m}} \mathrm{Tc}-$ radiocolloid to identify lymph nodes for resection and subsequent evaluation for cancer through touch preparation cytology or H\&E staining. Recently, the accuracy of nodal staging was challenged by the observed heterogeneity of outcomes for diagnosed node-negative $\left(\mathrm{pN}_{0}\right)$ breast cancer patients and the demonstrated improvement in the pathologic screening of resected nodes with molecularly specific immunohistochemistry as opposed to conventional cytology or frozen-section examination (26). Unfortunately, immunohistochemistry is time-consuming and often impractical for use in surgical pathology, in which immediate evaluation of the resected lymph nodes is required for surgical decision making. In addition, the supraclavicular nodes and internal mammary nodes that drain upper- and inner-quadrant lesions are not evaluated because of difficulties and complications in the surgical resection required for ex vivo pathology. For advanced disease, complete axillary lymph node dissection is automatically undertaken, because it is assumed that metastasis to the axillary lymph nodes has taken place even if no diagnostic evaluations were performed on internal mammary and supraclavicular nodes. Enhancing the accuracy of nodal staging with dually labeled, molecularly specific NIR and nuclear agents may offer opportunities to noninvasively stage early disease (inclusive of internal mammary and supraclavicular nodes), to enable longer times for clearance from normal, noncancerous tissues, to intraoperatively guide the resection of occult cancer-positive nodes and, finally, to accurately evaluate resected cancer-positive tissue through NIR fluorescence microscopy and $\gamma$-counting. In the present study, we demonstrated the targeting capabilities of dual-labeled $\left({ }^{111} \text { In-DTPA }\right)_{n}$-trastuzumab-(IRDye 800$)_{m}$ with in vitro microscopy and with standard in vivo models of subcutaneous xenografts after intravenous administration.

Although systemic intravenous administration may enable the detection of metastases, as suggested by the results obtained with standard subcutaneous tumor models, the assessment of occult lymph node metastases after intravenous administration requires either efficient extravasation into interstitial tissues and uptake into the lymphatics or direct extravasation into the lymph capsule. Unfortunately, antibody size prevents the former, and diagnostic doses 

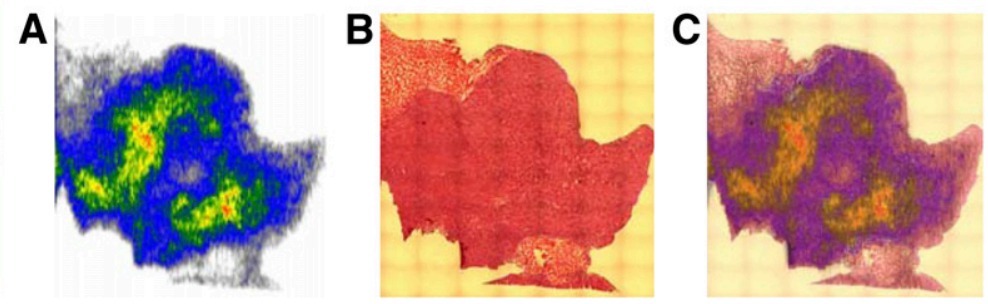

FIGURE 6. (A and B) Autoradiography signal from tumor tissue section of SKBr3-luc tumor-bearing mouse injected with $\left({ }^{111} \text { In-DTPA }\right)_{n}$-trastuzumab$(\text { IRDye800 })_{m}$ (A) overlaid on pathologic $\mathrm{H} \& \mathrm{E}$ staining (B) of same tissue section. (C) Coregistration of 2 images revealed that imaging agent bound specifically to tumor.

would have to be significantly elevated to account for limitations of transport of occult lymph node metastases from the vascular space. Figure 7 shows that intradermal injection of the imaging agent resulted in lymphatic uptake and, most importantly, clearance from the sentinel or nearest lymph nodes relative to the injection sites (popliteal lymph nodes). The intradermal administration of labeled antibodies may enable efficient delivery to the lymphatic space for the noninvasive detection of metastases, as first proposed by Weinstein et al. $(27,28)$ and Steller et al. (29). With the addition of NIR technology to the armamentarium of nuclear imaging techniques, the opportunity for molecular imaging for surgical guidance and noninvasive imaging of cancer-positive nodes could be realized. Recently, using a swine model, Sharma et al. demonstrated the ability to image lymph propulsion after intradermal delivery of a nonspecific NIR agent, indocyanine green (30). More recently, we similarly imaged lymph propulsion from the site of intradermal administration of $10-100 \mu \mathrm{g}$ of indocyanine green to the axillary lymph node basin in breast cancer patients (31). Although the preclinical animal models demonstrated the potential efficacy of ( ${ }^{111}$ In-DTPA) ${ }_{n}$-trastuzumab(IRDye800) $)_{m}$, human trials will need to be conducted to prove benefit. However, the opportunity for molecular reporting of occult micro- and nanometastases in HER2-overexpressing breast cancer patients through both optical imaging and nuclear imaging might increase the accuracy of TNM staging.

\section{CONCLUSION}

In this study, we demonstrated the molecular specificity of an antibody-based, dual-labeled imaging agent targeting HER2 in cell lines as well as in a standard subcutaneous animal model of human breast cancer. In vitro and in vivo results confirmed the molecular specificity of targeting, and there was a statistical correlation between nuclear and optical imaging results, confirming the stability of the dual-labeled
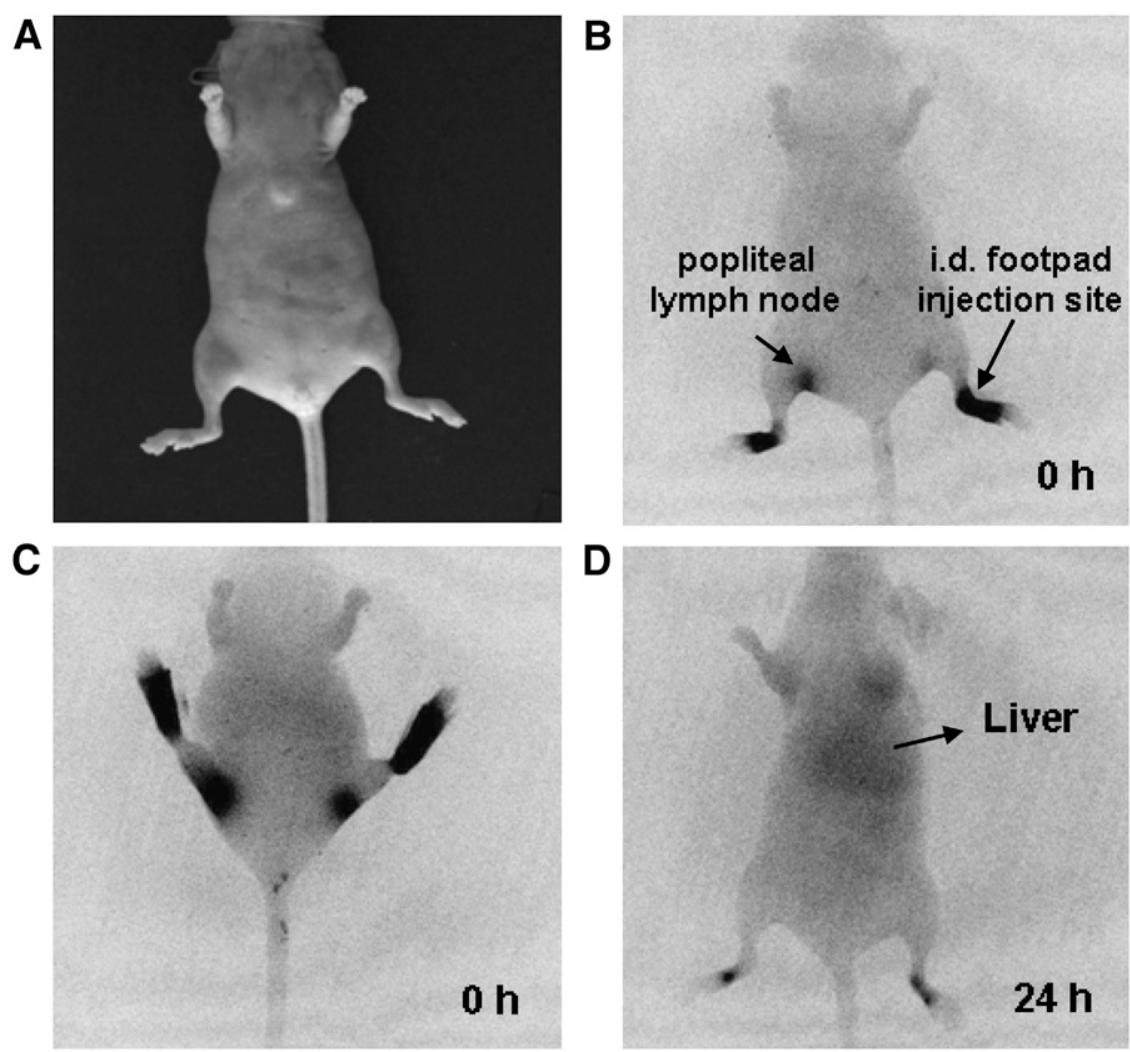

FIGURE 7. (A) White-light image shown for reference. (B and C) $\left({ }^{111} \ln -D T P A\right) n^{-}$ trastuzumab-(IRDye $800 \mathrm{CW})_{m}$ was injected intradermally (i.d.) into footpad of tumor-free mouse. Imaging agent immediately traveled through lymphatic channels and drained into popliteal lymph nodes. (D) Within $24 \mathrm{~h}$, agent was shown to be cleared from lymph nodes and footpad injection site. Accumulation in liver suggested antibody degradation for clearance. 
agent. Finally, we showed the ability to deliver the antibody-based agent into the lymphatics through intradermal injection as well as clearance from the regional lymphatic space after $24 \mathrm{~h}$.

\section{ACKNOWLEDGMENTS}

This work was supported in part by National Institutes of Health grants P50 CA58183, R01 EB003132, and R01 CA112679. We would like to acknowledge the Dan L. Duncan Cancer Center Protein Chemistry/MS-Based Proteomics Shared Resource at Baylor College of Medicine for assistance with the mass spectrometry experiments.

\section{REFERENCES}

1. Houston JP, Ke S, Wang W, Li C, Sevick-Muraca EM. Quality analysis of in vivo near-infrared fluorescence and conventional gamma images acquired using a dual-labeled tumor-targeting probe. J Biomed Opt. 2005;10:054010.

2. Slamon DJ, Godolphin W, Jones LA, et al. Studies of the HER-2/neu protooncogene in human breast and ovarian cancer. Science. 1989;244:707-712.

3. Carter P, Presta L, Gorman CM, et al. Humanization of an anti-p185HER2 antibody for human cancer therapy. Proc Natl Acad Sci USA. 1992;89:42854289.

4. Yeon CH, Pegram MD. Anti-erbB-2 antibody trastuzumab in the treatment of HER2-amplified breast cancer. Invest New Drugs. 2005;23:391-409.

5. Tokunaga E, Oki E, Nishida K, et al. Trastuzumab and breast cancer: developments and current status. Int J Clin Oncol. 2006;11:199-208.

6. Regitnig P, Schippinger W, Lindbauer M, Samonigg H, Lax SF. Change of HER-2/neu status in a subset of distant metastases from breast carcinomas. J Pathol. 2004;203:918-926.

7. Simon R, Nocito A, Hubscher T, et al. Patterns of her-2/neu amplification and overexpression in primary and metastatic breast cancer. J Natl Cancer Inst. 2001;93:1141-1146.

8. Pectasides D, Gaglia A, Arapantoni-Dadioti P, et al. HER-2/neu status of primary breast cancer and corresponding metastatic sites in patients with advanced breast cancer treated with trastuzumab-based therapy. Anticancer Res. 2006;26: 647-653.

9. Gong Y, Booser DJ, Sneige N. Comparison of HER-2 status determined by fluorescence in situ hybridization in primary and metastatic breast carcinoma. Cancer. 2005;103:1763-1769.

10. Carlsson J, Nordgren H, Sjostrom J, et al. HER2 expression in breast cancer primary tumours and corresponding metastases: original data and literature review. Br J Cancer. 2004;90:2344-2348.

11. Smith-Jones PM, Solit DB, Akhurst T, Afroze F, Rosen N, Larson SM. Imaging the pharmacodynamics of HER2 degradation in response to Hsp90 inhibitors. Nat Biotechnol. 2004;22:701-706.

12. Blend MJ, Stastny JJ, Swanson SM, Brechbiel MW. Labeling anti-HER2/neu monoclonal antibodies with ${ }^{111}$ In and ${ }^{90} \mathrm{Y}$ using a bifunctional DTPA chelating agent. Cancer Biother Radiopharm. 2003;18:355-363.
13. Tang Y, Wang J, Scollard DA, et al. Imaging of HER2/neu-positive BT-474 human breast cancer xenografts in athymic mice using (111)In-trastuzumab (Herceptin) Fab fragments. Nucl Med Biol. 2005;32:51-58.

14. Dennis MS, Jin H, Dugger D, et al. Imaging tumors with an albumin-binding Fab, a novel tumor-targeting agent. Cancer Res. 2007;67:254-261.

15. Tang Y, Scollard D, Chen P, Wang J, Holloway C, Reilly RM. Imaging of HER2/ neu expression in BT-474 human breast cancer xenografts in athymic mice using [(99m)Tc]-HYNIC-trastuzumab (Herceptin) Fab fragments. Nucl Med Commun. 2005;26:427-432.

16. Hilger I, Leistner Y, Berndt A, et al. Near-infrared fluorescence imaging of HER-2 protein over-expression in tumour cells. Eur Radiol. 2004;14:1124-1129.

17. Watanabe TM, Tada H, Higuchi H, Ohuchi N. Reduction in nonfluorescence state of quantum dots on an immunofluorescence staining. Biochem Biophys Res Commun. 2006;351:7-13.

18. Tada H, Higuchi H, Watanabe TM, Ohuchi N. In vivo real-time tracking of single quantum dots conjugated with monoclonal anti-HER2 antibody in tumors of mice. Cancer Res. 2007;67:1138-1144.

19. Huh YM, Jun YM, Song HT, et al. In vivo magnetic resonance detection of cancer by using multifunctional magnetic nanocrystals. J Am Chem Soc. 2005; 127:12387-12391.

20. Artemov D, Mori N, Okollie B, Bhujwalla ZM. MR molecular imaging of the Her-2/neu receptor in breast cancer cells using targeted iron oxide nanoparticles. Magn Reson Med. 2003;49:403-408.

21. Copland JA, Eghtedari M, Popov VL, et al. Bioconjugated gold nanoparticles as a molecular based contrast agent: implications for imaging of deep tumors using optoacoustic tomography. Mol Imaging Biol. 2004;6:341-349.

22. Perik PJ, Lub-de Hooge MN, Gietema JA, et al. Indium-111-labeled trastuzumab scintigraphy in patients with human epidermal growth factor receptor 2-positive metastatic breast cancer. J Clin Oncol. 2006;24:2276-2282.

23. Lindmo T, Boven E, Cuttitta F, Fedorka J, Bunn PA. Determination of the immunoreactive fraction of radiolabeled monoclonal antibodies by linear extrapolation to binding at infinite antigen excess. J Immunol Methods. 1984;72: 77-89.

24. Behr TM, Behe M, Wormann B. Trastuzumab and breast cancer. N Engl J Med. 2001;345:995-996.

25. Lub-de Hooge MN, Kosterink JG, Perik PJ, et al. Preclinical characterisation of ${ }^{111}$ In-DTPA-trastuzumab. Br J Pharmacol. 2004;143:99-106.

26. Querzoli P, Pedriali M, Rinaldi R, et al. Axillary lymph node nanometastases are prognostic factors for disease-free survival and metastatic relapse in breast cancer patients. Clin Cancer Res. 2006;12:6696-6701.

27. Weinstein JN, Parker RJ, Keenan AM, Dower SK, Morse HC, Sieber SM. Monoclonal antibodies in the lymphatics: toward the diagnosis and therapy of tumor metastases. Science. 1982;218:1334-1337.

28. Weinstein JN, Stellar MA, Keenan AM, et al. Monoclonal antibodies in the lymphatics: selective delivery to lymph node metastases of a solid tumor. Science. 1983;222:423-426.

29. Steller MA, Parker RJ, Covell DG, et al. Optimization of monoclonal antibody delivery via the lymphatics: the dose dependence. Cancer Res. 1986;46:18301834 .

30. Sharma R, Wang W, Rasmussen JC, et al. Quantitative imaging of lymph function. Am J Physiol Heart Circ Physiol. 2007;292:H3109-H3118.

31. Sevick-Muraca EM, Sharma R, Rasmussen JC, et al. Imaging of lymph flow in breast cancer patients after microdose administration of a near-infrared fluorophore. Radiology. Accepted. 